\title{
Perancangan Basis Data Katalog Citra Satelit LAPAN
}

\author{
Agus Herawan ${ }^{1}$, Sartika Salaswati ${ }^{2}$ \\ ${ }^{1}$ Pusat Teknologi Satelit - LAPAN \\ e-mail: agus.herawan@lapan.go.id \\ ${ }^{2}$ Pusat Teknologi Satelit - LAPAN \\ e-mail: sartika.salas@gmal.com
}

\begin{abstract}
Abstrak
Satelit LAPAN-A2/LAPAN-Orari dan LAPAN-A3/LAPAN-IPB telah menghasilkan sejumlah citra satelit sejak peluncuran di, Sriharikota India, pada tahun 2015 dan 2016. LAPAN berharap bahwa hasil tracking satelit membutuhkan media penyimpanan yang memungkinkan untuk menjadi lebih mudah diakses dan menarik bagi publik. Hasil citra sampai saat ini hanya tersimpan pada folder-folder dengan penamaan khusus. Metode tersebut cenderung manual dan menyulitkan operator untuk mencari citra dengan spesifikasi tertentu. Disamping itu, kebutuhan pengguna terhadap data citra pada waktu tertentu menjadi permasalahan utama. Stasiun bumi satelit LAPAN setiap hari secara rutin melakukan kegiatan akuisisi dan pengolahan data citra satelit LAPAN. Data citra satelit LAPAN hasil pengolahan di stasiun bumi ini kemudian diintegrasikan ke dalam satu sistem katalog dengan sinkronisasi informasi hasil pengolahan data. Oleh karena itu, fasilitas ini dirancang dan diimplementasikan untuk memenuhi persyaratan pengguna. Makalah ini akan memaparkan rancang bangun sistem baisis data katalog citra satelit LAPAN yang berbasis web dan near-real time. Sistem basis data katalog ini diharapkan dapat memudahkan pengguna di seluruh Indonesia untuk mengakses dan mengunduh data citra satelit LAPAN secara langsung.Disamping sebagai media penyimpanan, dengan menggunakan katalog citra berbasis web akan mempermudah Pusteksat untuk mendiseminasikan produk satelit LAPAN
\end{abstract}

Kata Kunci: Satelit, LAPAN-A2, LAPAN-A3, katalog, basis data

\begin{abstract}
The LAPAN-A2 / LAPAN-Orari and LAPAN-A3 / LAPAN-IPB satellites have produced a number of satellite imagery since the launch at, Sriharikota India, in 2015 and 2016. LAPAN hopes that the results of satellite tracking require storage media that allows it to be more accessible and attractive to the public. Image results to date have only been stored in folders with special names. The method tends to be manual and makes it difficult for operators to find images with certain specifications. In addition, user needs for image data at certain times become the main problem. The LAPAN satellite earth station routinely conducts acquisition and processing of LAPAN satellite image data every day. The LAPAN satellite image data from the processing at this earth station is then integrated into one catalog system by synchronizing information from the data processing. Therefore, this facility is designed and implemented to meet user requirements. This paper will describe the design of a web and near-real-time LAPAN satellite image catalog data analysis system. This catalog database system is expected to facilitate users throughout Indonesia to access and download LAPAN satellite image data directly. Aside from being a storage media, using a web-based image catalog will make it easier for Pusteksat to disseminate LAPAN satellite products.
\end{abstract}

Keywords: Satellite, LAPAN-A2, LAPAN-A3, catalogue, database

\section{Pendahuluan}

Satelit LAPAN-A2 adalah satelit generasi ke dua buatan Indonesia yang diluncurkan pada tanggal 28 september 2015 dengan menggunakan wahana peluncur PSLV C-30 milik India. Satelit ini memiliki misi diantaranya untuk pemantauan permukaan Bumi (Hardhienata, Triharjanto, \& Mukhayadi, 2011). Sesuai dengan misi tersebut, satelit 
ini dibekali dengan 2 buah kamera yaitu kamera video dan kamera digital resolusi tinggi (Space Cam). Kamera video satelit LAPAN A2 memiliki sensor dengan ukuran $752 \times 582$ pixel dengan resolusi $6 \mathrm{~m}$ dan swath $5 \mathrm{~km}$ pada ketinggian $630 \mathrm{~km}$. Sedangkan kamera digital memiliki sensor dengan ukuran 2048 x 2048 pixel dengan resolusi $4 \mathrm{~m}$ dan swath $7 \mathrm{~km}$ pada ketinggian yang sama. Satelit LAPAN-A3 diluncurkan dengan Roket PSLV C-34 dari Bandar Antariksa Satish Dhawan, Sriharikotta, India, Rabu, 22 Juni 2016. LAPAN-A3/LAPAN-IPB memiliki berat 115 $\mathrm{kg}$ dengan ketinggian (altitude) $508 \mathrm{~km}$ (Syafrudin, Hasbi, \& Rahman, 2013). Sama halnya dengan satelit LAPAN-A2, satelit LAPAN-A3 memiliki muatan optik didalamnya, yaitu LISA (Line Imager Space Application), Space Cam, Kamera Video, dan Microbolometer. Satelit LAPAN-A2 dan LAPAN-A3 telah banyak menghasilkan citra baik citra Space Cam LAPAN-A2 dan LAPAN-A3 maupun citra LISA LAPAN-A3 (Saifudin \& Mukhayadi, 2013). Ilustrasi pergerakkan satelit LAPAN-A2 dan LAPANA3 disajikan pada Gambar 1.

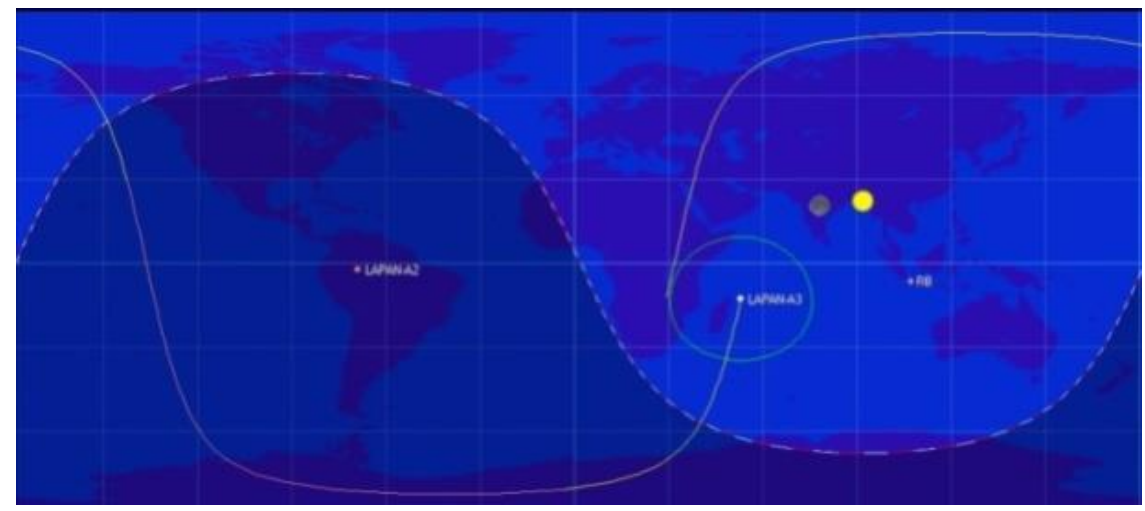

Gambar 1. Satelit LAPAN-A2 dan A3 ketika berada di orbit

Akuisisi citra dari satelit diperoleh dari beberapa stasiun bumi penerima data satelit. Adapun staisun bumi penerima satelit LAPAN yakni berada di Rancabungur, Pare-pare, Biak dan Spitsbergen. Hasil citra sampai saat ini hanya tersimpan pada folder-folder dengan penamaan khusus. Metode tersebut cenderung manual dan menyulitkan operator untuk mencari citra dengan spesifikasi tertentu. Disamping itu, kebutuhan pengguna terhadap data citra pada waktu tertentu menjadi permasalahan utama. Data citra yang terpisah-pisah dan tidak tersusun dengan rapih memungkinkan data citra sulit untuk diakses. Sejalan dengan hal itu citra satelit terus bertambah setiap harinya. Hal ini menyebabkan data citra yang dihasilkan oleh satelit memerlukan tempat penyimpanan dengan kapasitas besar 


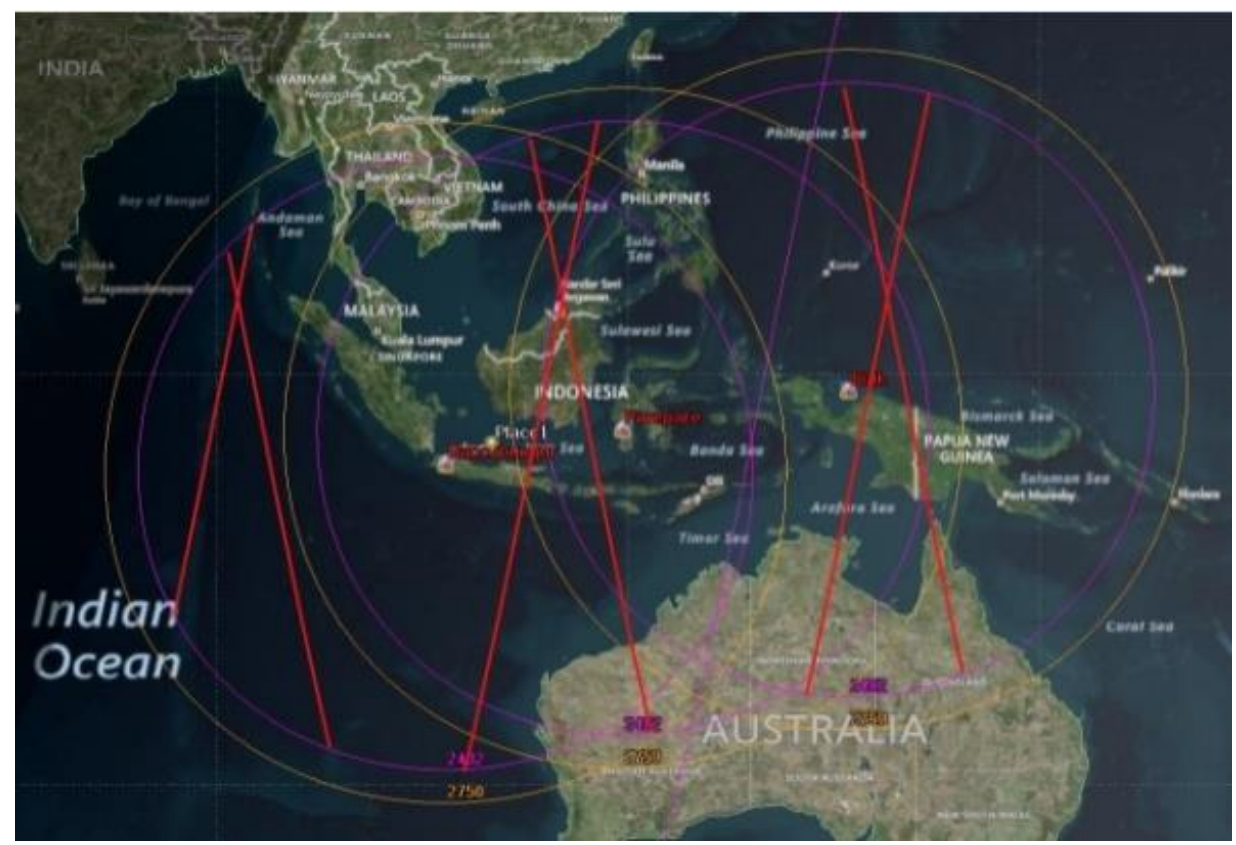

Gambar 2. Stasiun Bumi Penerima Citra Satelit LAPAN

Beberapa penelitian terkaiit yakni pengembangan aplikasi yang katalog citra satelit dikembangkan untuk kebutuhan pengguna terkait dengan pemanfaatan citra satelit untuk berbagai aplikasi. Berdasarkan analisis kebutuhan pengguna, sistem harus ditingkatkan dalam tiga faktor, yaitu waktu transaksi, derivasi produk, dan layanan pemrosesan data tambahan (Setiyoko et al., 2018).

Penelitian yang dilakukan oleh (Linda, 2016) telah merancang e-katalog pada Badan Perpustakaan Arsip dan Dokumentasi Daerah Lampung. E-katalog yang di rancang akan mempermudah pihak perpustakaan khususnya pengelola persedian buku dan pengelola informasi dalam publikasi serta mempermudah masyarakat dalam pengaksesan koleksi. Pengembangan katalog juga dilakukan pada penelitian

Penelitian (Hardhienata \& Dewi, 2009) mengembangkan galeri video interaktif hasil satelit LAPAN-TUBSAT. Penelitian ini berhasil mengimplementasikan animasi dan pemutar video pada situs Lapan Polar Satellites. Saat ini, Pusteksat belum memiliki sistem pencarian katalog yang siap operasional berbasis web. Sistem katalog yang akan dirancang ini dalam rangka menjalankan fungsi pelayanan atau diseminasi data citra satelit LAPAN-A2 dan LAPAN-A3. Penelitian (Miyazaki, Iwao, \& (Miyazaki, Iwao, \& Shibasaki, 2012) mengembangkan suatu algoritma untuk menentukan kombinasi citra satelit sesuai dengan tingkat pengamatan dan kualitas gambar. Algoritma ini untuk menguji kebutuhan untuk menyelesaikan cakupan dari jangkauan pencarian.Penerapan metode ini ke database metadata gambar satelit ASTER yang diarsipkan di GEO Grid Institut Nasional Teknologi dan Sains Industri Maju (AIST), Jepang. Metodologi perancangan adalah pendekatan terstruktur dengan menggunakan prosedur, teknik, alat, serta bantuan dokumen untuk membantu dan memudahkan dalam proses perancangan.

Penggunaan metode ini dapat membantu dalam merencanakan, mengatur, mengontrol, dan mengevaluasi database development project (Connolly \& Begg, 2010). Penelitian (Adityawarman, 2016) telah mengimplementasikan problem based learning untuk meningkatkan kemampuan mahasiswa dalam merancang basis data.

Dalam merancang suatu basis data, digunakan metodologi-metodologi yang dapat membantu dalam setiap tahap perancangan basis data. Metodologi perancangan adalah pendekatan terstruktur dengan menggunakan prosedur, teknik, alat, serta bantuan dokumen untuk membantu dan memudahkan dalam proses perancangan. Penggunaan metode ini dapat membantu dalam merencanakan, mengatur, mengontrol, dan mengevaluasi database development project (Connolly \& 
Begg, 2010). Penelitian (Adityawarman, 2016) telah mengimplementasikan problem based learning untuk meningkatkan kemampuan mahasiswa dalam merancang basis data

Sementara Penelitian ( Firmansyah \& Saidah, 2016) telah melakukan perancangan web based learning sebagai media pembelajaran berbasis ICT. Aplikasi katalog yang akan dikembangkan tersebut merupakan salah satu sarana penghubung atau sarana komunikasi dengan pengguna (user) yang membutuhkan informasi dan data citra dari kedua satelit tersebut. Aplikasi katalog terdiri dari 2 bagian, yaitu bagian front-end dan back-end. Perlu adanya penambahan fitur-fitur yang terdapat dalam pencarian katalog untuk meningkatkan fungsionalitasnya dalam menjalankan fungsi diseminasi data.

Untuk mengatasi permasalahan tersebut, maka dirancang sebuah prototype sistem katalog citra satelit LAPAN berbasis web. Disamping sebagai media penyimpanan, dengan menggunakan katalog citra berbasis web akan mempermudah Pusteksat untuk mendiseminasikan produk satelit LAPAN

\section{MetodePenelitian}

Adapun metodologi yang akan digunakan dalam penelitian ini disajikan pada Gambar 3.

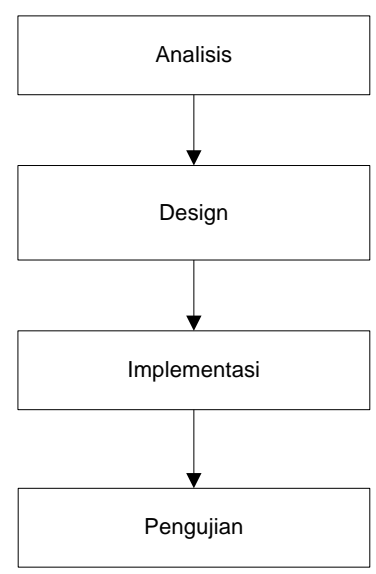

Gambar 3. Metodologi Penelitian

Metode yang digunakan antara lain :

\section{a. Analisis}

Proses pengumpulan kebutuhan dilakukan secara intensif untuk menspesifikasikan kebutuhan perangkat lunak agar dapat dipahami perangkat lunak seperti apa yang dibutuhkan oleh user. Spesifikasi kebutuhan perangkat lunak pada tahap ini perlu untuk didokumentasikan.

b. Desain

Desain perangkat lunak adalah proses multilangkah yang fokus pada desain pembuatan program perangkat lunak termasuk struktur data, arsitektur perangkat lunak, representasi antar muka, dan prosedur pengodean. Tahap ini mentranslasi kebutuhan perangkat lunak dari tahap analisis kebutuhan ke representasi desain agar dapat diimplementasikan menjadi program pada tahap selanjutnya. Desain perangkat lunak yang dihasilkan pada tahap ini juga perlu didokumentasikan.

\section{c. Implementasi}

Desain harus ditranslasikan ke dalam program perangkat lunak. Hasil dari tahap ini adalah program komputer sesuai dengan desain yang telah dibuat pada tahap desain.

\section{d. Pengujian}

Pengujian fokus pada perangkat lunak secara dari segi lojik dan fungsional dan memastikan bahwa semua bagian sudah diuji. Hal ini dilakukan untuk meminimalisir kesalahan dan memastikan keluaran yang dilakukan sesuai dengan yang diinginkan.

\section{Hasil Dan Pembahasan}

Untuk melihat proses perancangan basis data katalog ini dilakukan dengan teknik ERD ( Entitiy Relationship Diagram) dan DFD ( Data Flow Diagram)

\subsection{Analisis}

Analisis pada basis data katalog ini terdiri atas analisis konten, analisis interaksi, analisis kebutuhan, dan analisis konfigurasi. Katalog ini dibangun oleh beberapa bagian dalam sebuah pemodelan database. Secara ringkas, pemodelan ini terdiri dari user management, upload, image. Pemodelan data pada system baiss data katalog ini dibuat dengan model sistem basis data relasional dengan struktur ERD. Sistem basis data ini diolah dengan MySQL.

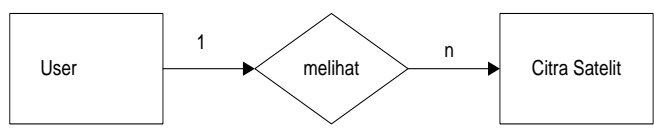

Analisis interaksi pada sistem katalog ini merupakan hubungan antara pengguna dengan sistem katalog. Interaksi yang 
terjadi dibagi menjadi dua bagian, yakni interaksi secara umum dan secara khusus. Gambar 4. ERD Katalog Citra Satelit
Diagram konteks katalog citra satelit LAPAN disajikan pada Gambar 5.

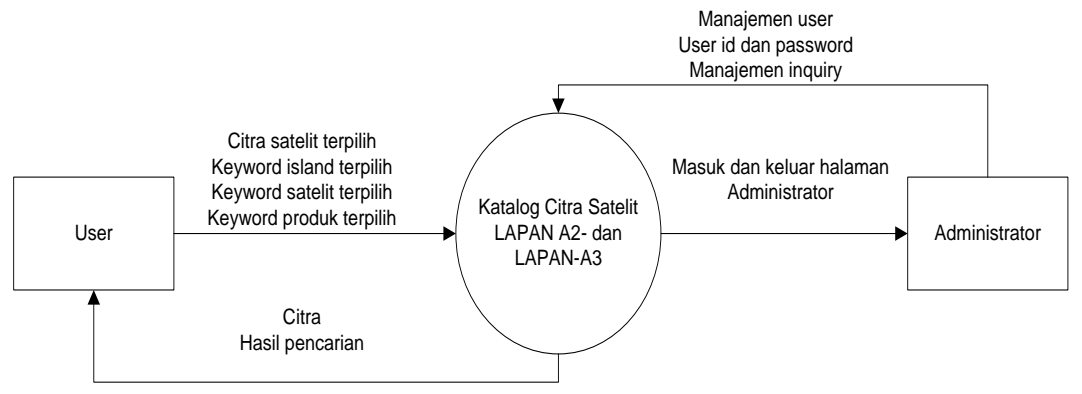

Gambar 5. Diagram Konteks

Pada gambar 5, dijelaskan interaksi yang terjadi dilakukan oleh pengguna maupun administrator dengan sistem katalog dimulai dengan proses pemasukkan data oleh administrator ke dalam database system. Selanjutnya katalog akan menampilkan informasi kepada user. User dapat melakukan pencarian dengan tiga cara, yaitu: memilih propinsi, memilih produk citra satelit, memilih satelit melakukan pencarian pada menu search dengan memasukkan keyword (kata kunci), dan pada halaman pencarian untuk pencarian secara rinci. Setelah itu, sistem akan memberikan keluaran berupa citra yang sesuai dengan keyword yang telah dimasukkan. Data yang telah dikeluarkan selebihnya dapat di lihat dan diunduh user.

Selanjutnya Analisis kebutuhan non fungsional menggambarkan kebutuhan sistem yang menitikberatkan pada properti prilaku yang dimiliki oleh sistem, diantaranya kebutuhan perangkat lunak, perangkat keras, serta pengguna system (user) sebagai bahan analisis kekurangan dan kebutuhan yang harus dipenuhi dalam perancangan sistem yang akan diterapkan. Analisis kebutuhan fungsional menggambarkan proses kegiatan yang akan diterapkan dalam sebuah sistem dan menjelaskan kebutuhan yang diperlukan sistem agar sistem dapat berjalan dengan baik serta sesuai dengan kebutuhan.

\subsection{Perancangan Basis Data}

Perancangan basis data katalog ini meliputi perancangan struktur data, arsitektural, navigasi, subsistem antarmuka, serta antarmuka. Adapun katalog ini dirancang dengan menggunakan 6 tabel yakni tabel_Satelit, tabel_Citra_LISA, tabel Citra SpaceCam, tabel User dan tabel wilayah

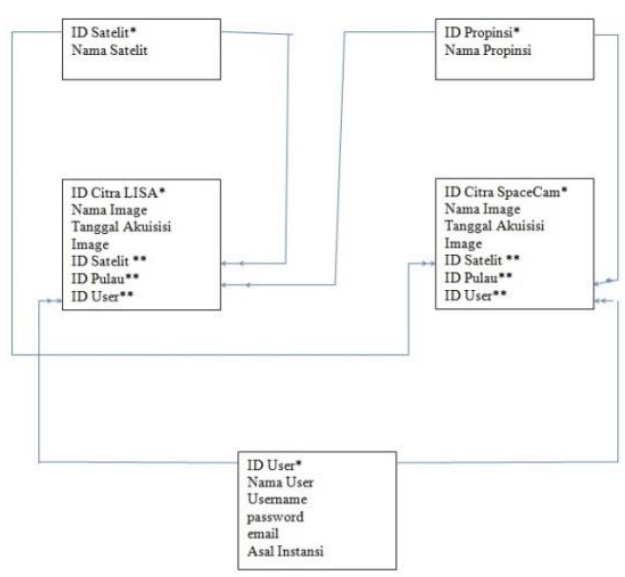

Gambar 6. Relasi Antar Tabel pada Basis Data Katalog Citra Satelit LAPAN

\subsection{Perancangan Antarmuka Galeri Citra Satelit.}

Selain menyediakan halaman informasi tentang satelit, pengguna juga dapat melihat keseluruhan citra hasil tracking Satelit LAPAN secara lebih lengkap pada halaman image collection. Halamnini dirancang sedemikian sehingga masing-masing satelit memiliki informasi mengenai data apa saja yang telah dihasilan.

\subsection{Tampilan Antar Muka}

Sistem basis data katalog diimplementasikan dengan bahasa pemrograman PHP dan SQL. Implementasi meliputi implementasi antar muka serta galeri citra satelit itu sendiri. Tampilan antar muka utama pembuka katalog citra satelit disajikan pada Gambar 7. 


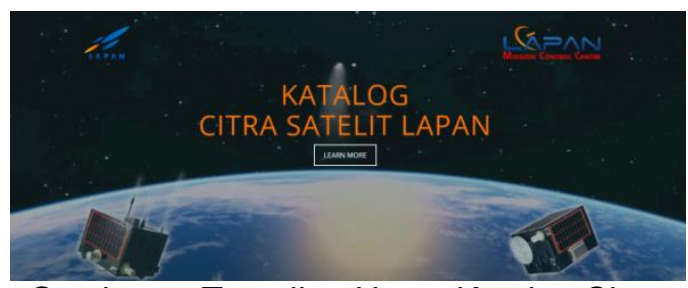

Gambar 7..Tampilan Home Katalog Citra Satelit LAPAN

Setelah pengguna masuk ke tampilan utama, selanjutnya pengguna diarahkan ke dalam halaman informasi mengenai satelit yang datanya akan digunakan dalam katalog ini. Selain itu, di tampilkan juga informasi mengenai satelitsatelit LAPAN yang telah menghasilan citra. dalam sistem ini ditampilkan informasi tentang satelit LAPAN-A2 dan LAPAN-A3. Tampilan informasi satelit disajikan pada Gambar 8.

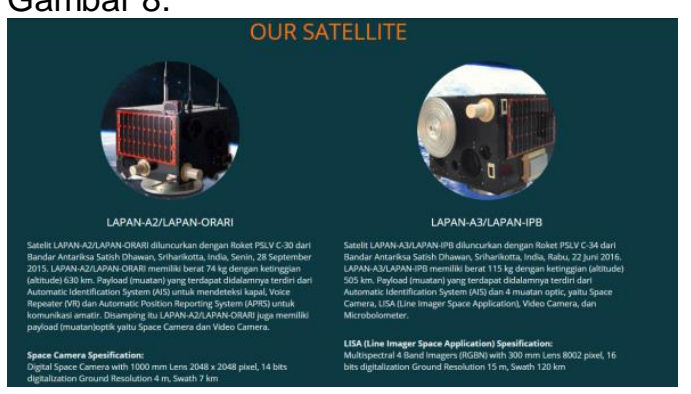

Gambar 8..Tampilan Informasi Satelit Pada Katalog Citra Satelit LAPAN

Selanjutnya pada halaman koleksi citra satelit, user dapat melakukan pencarian dengan menggunakan keyword. Setelah memasukkan keyword, proses selanjutnya akan melakukan koneksi ke database, kemudian sistem akan mencari data yang berkaitan dengan keyword. Proses pencarian diperinci dengan menggunakan beberapa kategori, yaitu tanggal akuisisi, propinsi atau island, produk satelit ( LISA atau Spacecam ), dan satelit (LAPAN-A2 dan LAPAN-A3). Tampilan galeri citra satelit disajikan pada Gambar 9.

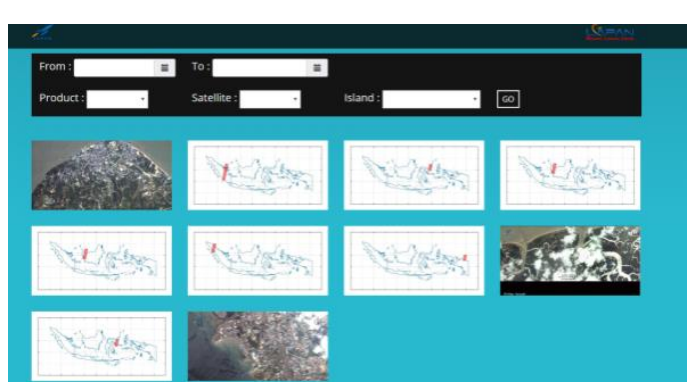

Gambar 9.
.Tampilan Pencarian Citra Pada Katalog Citra Satelit LAPAN

Setelah memilih citra yang diinginkan, user dapat melihat serta mengunduh citra itu sendiri. Tampilan unduh disajikan pada Gambar 10.

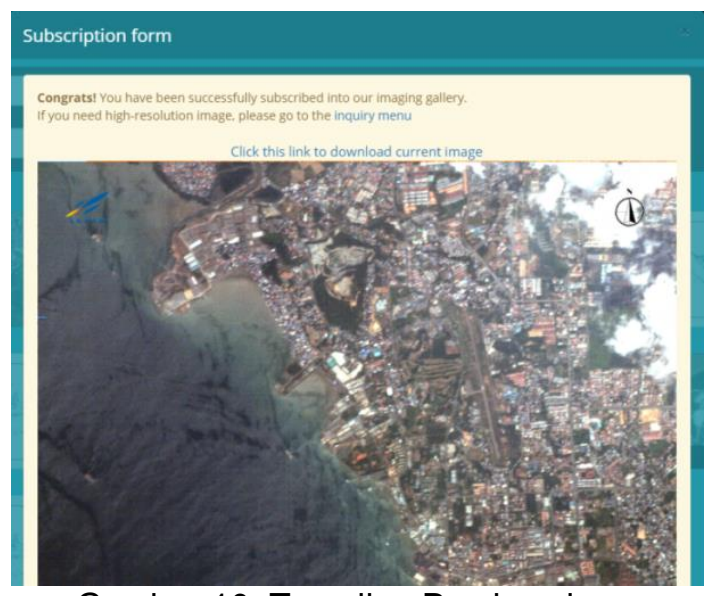

Gambar 10..Tampilan Preview dan

Download Citra Pada Katalog Citra Satelit LAPAN

\subsection{Pengujian}

Setelah proses implementasi dilakukan, tahap selanjutnya adalah melakukan pengujian terhadap sistem untuk mengetahui apakah sistem telah berfungsi dengan baik dan benar atau tidak sesuai keinginan user. Proses pengujian sangat sesuai dengan yang diharapkan. Task-task telah terpenuhi dengan baik. Hasil pengujian disajikan dalam skenario pengujian yang dapat dilihat pada Tabel 1.

Tabel 1. Pengujian Sistem

\begin{tabular}{|l|l|l|l|}
\hline $\begin{array}{c}\mathbf{N} \\
\mathbf{0}\end{array}$ & Aplikasi & Deskripsi Uji & $\begin{array}{c}\text { Ha } \\
\text { sil } \\
\text { Uji }\end{array}$ \\
\hline 1 & $\begin{array}{c}\text { Memilih } \\
\text { Propinsi / } \\
\text { Island }\end{array}$ & $\begin{array}{c}\text { Memilih Citra } \\
\text { satelit } \\
\text { berdasarkan } \\
\text { kategori } \\
\text { propinsi/islan } \\
\text { d }\end{array}$ & $\mathrm{O}$ \\
\hline 2 & Kemilih \\
$\cdot$ & $\begin{array}{c}\text { Memih Citra } \\
\text { satelit } \\
\text { berdasarkan } \\
\text { kategori } \\
\text { satelit }\end{array}$ & $\mathrm{K}$ \\
\hline 3 & $\begin{array}{c}\text { Memilih } \\
\text { produk } \\
\text { Satelit }\end{array}$ & $\begin{array}{c}\text { Memilih Citra } \\
\text { satelit } \\
\text { berdasarkan } \\
\text { produk satelit }\end{array}$ & $\mathrm{O}$ \\
\hline
\end{tabular}




\section{Kesimpulan}

Berdasarkan uraian yang telah diberikan di depan dapat diambil kesimpulan bahwa problem keterbatasan penyimpanan citra satelit LAPAN-A2 dan LAPAN-A3 dan masalah aksesabilitas serta problem interaksi dengan user dapat diatasi dengan pembangunan katalog citra satelit LAPAN. Dengan adanya katalog ini maka citra baik itu LISA maupun SpaceCam hasil akuisisi satelit LAPAN-A2 dan LAPAN-A3 dapat diakses dengan mudah oleh masyarakat luas. Di samping itu, fasilitas pencarian berdasarkan kategori tertentu juga dapat membuat katalog ini dapat memberikan informasi hasil tracking satelit kepada pengunjung situs dengan lebih interaktif dan menarik. Selanjutnya penelitian selanjutnya, akan dilakukan pembacaan image yang telah dihasilkan satelit dengan format ektensi tiff.

\section{Referensi}

Adityawarman, D. (2016). Implementasi Problem Based Learning Untuk Meningkatkan Kemampuan Dalam Merancang Basis Data. Informatika

Connolly, T., \& Begg, C. E. (2010). Database Systems: a practical approach to design, implementation, and management. Database Systems: a practical approach to design, implementation, and management.

Firmansyah, R., \& Saidah, I. (2016). Perancangan Web Based Learning Sebagai Media Pembelajaran Berbasis ICT. Informatika

Hardhienata, S., \& Dewi, M. K. (2009). Rancangan Dan Implementasi Galeri Video Pada Situs LAPAN Polar Satellites. JUTI

Hardhienata, S., Triharjanto, R. H., \& Mukhayadi, M. (2011). LAPAN-A2: Indonesian Near-Equatorial Surveilance Satellite. Presented at the 18th Asia-Pacific Regional Space Agency Forum (APRSAF), Singapore.

Linda, D. (2016). Merancang e-katalog Berbasis Website Sebagai Media Informasi pada Badan Perpustakaan Arsip dan Dokumentasi Daerah (BPAD) Lampung. Jurnal Sistem Informasi Dan Telematika.
Miyazaki, H., Iwao, K., \& Shibasaki, R. (2012). Automated Construction of Coverage Catalogues of Aster Satellite Image for Urban Areas of the World. The International Archives of the Photogrammetry, Remote Sensing and Spatial Information Sciences.

Saifudin, M. A., \& Mukhayadi, M. (2013). LAPAN-A2 Attitude Control Strategy for Equatorial Surveillance Mission. In Proc. of the 9th IAA Symposium on Small Satellites for Earth Observation.

Setiyoko, A., Meiyanti, R., Nurbojatmiko, Syamsudin, Sensuse, D. I., \& Noprisson, H. (2018). Satellite image catalog system improvement based on process innovation method. In AIP ConferenceProceedings.

https://doi.org/10.1063/1. 5042871

Syafrudin, A. H., Hasbi, W., \& Rahman, A. (2013). Camera payload systems for the LAPAN A2 experimental microsatellite. In 34th Asian Conference on Remote Sensing 2013, ACRS 2013. 